\title{
MiR-566 mediates cell migration and invasion in colon cancer cells by direct targeting of PSKH1
}

Ying Zhang', Siqi Zhang ${ }^{2}$, Jian Yin ${ }^{3}$ and Ruisi $\mathrm{Xu}^{1 *}$ (D)

\begin{abstract}
Background: Colorectal cancer (CRC), a common malignancy worldwide, and microRNAs (miRs) have been suggested to play roles in the disease. MiR-566 expression has been shown to be reduced in CRC, but its functions and mechanisms are still unclear.

Methods: Cell viability was assessed by using the CellTiter 96 AQueous One Solution Cell Proliferation kit. Cell proliferation was measured with MTT assay. Cell metastasis were measured by transwell assay. Luciferase reporter assays was used to confirm the target of MiR-566. PSKH1 expression was measured by RT-PCR and western blot.

Results: In the present study, we first observed that miR-566 was expressed in several CRC cell lines (SW480, SW620, LoVo, HT29 and (aco-2) at low levels compared to control colon epithelial cell lines (FHC). Further study showed that miR-566 overexpression suppressed cell survival and impeded cell proliferation, whereas inhibition of its expression enhanced cell survival and proliferation. Transwell assays showed that cell invasion and migration were reduced in cells overexpressing miR-566 and increased in those with inhibition of miR-566. Further analysis confirmed that PSKH1 is a target of miR-566. MiR-566 overexpression significantly inhibited PSKH1 expression and reintroduction of PSKH1 partially reversed the effects of miR-566 on CRC cell growth and metastasis in SW480 and Caco-2 cells.
\end{abstract}

Conclusions: Taken together, the data show that CRC cell growth and metastasis can be significantly suppressed by miR-566 through targeting PSKH1.

Keywords: Colorectal cancer, miR-566, PSKH1, Invasion, Migration

\section{Background}

Colorectal cancer (CRC), the most prevalent malignancy, is a complex polygenetic disease and the main cause of death from cancer worldwide [1, 2]. CRC-associated morbidity is increasing annually, and in 2008, there were approximately 120,0000 new CRC cases globally and more than 60,0000 deaths [3]. Death is caused by progression and metastasis of the cancer, and previous research implicates several underlying mechanisms in cancer metastasis, including tumor cell invasion, adhesion, chemotaxis, epithelial-mesenchymal transition and

\footnotetext{
*Correspondence: ruisi_xu1@163.com

${ }^{1}$ Endoscopy Center, China-Japan Union Hospital of Jilin University, No.

126 Sendai Street, Changchun 130033, Jilin, China

Full list of author information is available at the end of the article
}

tumor cell growth $[3,4]$. In recent years, the life expectancy of patients with CRC has improved because of the advances in screening and treatment; however, the prognosis remains poor in patients with metastatic cancer [5]. Thus, understanding how cancer metastasis proceeds and finding a way to block this process would be beneficial in developing cancer treatments.

MicroRNAs (miRNAs), a family of single-stranded, noncoding, short RNAs, have been shown to be involved in CRC metastasis [6-8]. miRNAs play inhibitory roles in the function of their target genes, with miRNAs binding to the 3' untranslated region (3'UTR) of target genes and then inhibiting gene translation or degrading the target mRNA [9]. Prior evidence suggests that miRNA may be used as a cancer therapy because it can interact with many target genes and signaling pathways that promote 
cancer cell death [10]. Li et al. [11] showed that miR-433 plays roles in inhibiting growth and promoting apoptosis through mediation of its target gene MACC1. In addition, Qin et al. [12] suggested that mir-106a regulates the PTEN/PI3K/AKT pathway and is associated with colon cancer cell growth. Multiple studies have implicated miRNAs play roles in colon cancer cell migration and invasion $[13,14]$. miR-566 has been shown to be decreased in CRC; however, its functions and mechanisms remain unknown [15]. The present study found that miR-566 has low expression in colon cancer cells and plays roles in cancer cell growth and metastasis.

Kim and his colleagues [16] found that three kinase genes, PHKG2, TLK2, and PSKH1, were all expressed in metastatic CRC at high level, and their overexpression may be a potential biomarker of cetuximab plus irinotecan induced-wild-type KRAS CRC. PSKH1, an autophosphorylating human protein serine kinase, has 424 amino acids and is localized to the Golgi apparatus and speckle structures within the nucleus $[17,18]$. In the current study, we confirmed that PSKH1 is a direct target of miR-566, and its expression was inhibited by miR566 overexpression; moreover, our study indicated that PSKH1 is involved in the function of miR-566 in CRC cell proliferation, migration, and invasion.

\section{Materials and methods}

\section{Cell culture and transfection}

The human colon cancer cell lines SW480, SW620, LoVo, Caco-2 and HT29 and human normal colon epithelial cell lines (FHC) were purchased from ATCC (Manassas, VA, USA). All cells were maintained in DMEM added with $100 \mu \mathrm{g} / \mathrm{mL}$ streptomycin, fetal bovine serum, $100 \mathrm{U} / \mathrm{mL}$ penicillin. Cells were cultured in a $5 \% \mathrm{CO}_{2}$ atmosphere at $37^{\circ} \mathrm{C}$.

For transfection, micro-RNAs [19] used in this study were all obtained from GenePharma (Shanghai, China). Lipofectamine ${ }^{\circledR}$ RNAiMAX Transfection Reagent (Invitrogen, Carlsbad, CA) were used to transfected miR566 mimic (F: 5'-GGGCGCCUGUGAUCCCAAC-3'; R: 5'-UGGGAUCACAGGCGCCCUU-3'), mimic control (NC: F: 5'-UUCUCCGAACGUGUCACGUTT-3'; R: $5^{\prime}$-ACGUGACACGUUCGGAGAATT-3'), miR-566 inhibitor (5'-GUUGGGAUCACAGGCGCCC-3') and inhibitor control (anti-NC: $5^{\prime}$-CAGUACUUUUGUGUA GUACAA-3') into human colon cancer cells. For further studies of the mechanism, SW480 and Caco- 2 cells were co-transfected with miR-566 mimic and pcDNA3.1PSKH1 vector and cultured for $48 \mathrm{~h}$.

\section{Cell survival}

SW480, SW620 or Caco-2 cell viability was assessed by using the CellTiter 96 AQueous One Solution Cell
Proliferation kit (Promega, Madison, WI, USA) following the manufacturer's instructions.

\section{Cell proliferation}

SW480, SW620 or Caco-2 cell proliferation was measured with MTT assay. Cells were transfected with miR566 mimic, NC, miR-566 inhibitor, and anti-NC for $48 \mathrm{~h}$, and MTT $(20 \mu \mathrm{L}, 5 \mathrm{mg} / \mathrm{mL})$ was added to cells for another $4 \mathrm{~h}$. Cell proliferation was determined by quantification of the absorbance at $490 \mathrm{~nm}$ by using a microplate reader.

\section{Transwell assay}

SW480 or SW620 or Caco-2 cell metastasis were measured by transwell assay. SW480 or SW620 cells at a density of $1 \times 10^{5}$ were plated into the upper transwell chamber. For the invasion assay, the upper transwell chamber was coated with Matrigel, and for the migration assay, the chamber was uncoated. The lower transwell chamber contained the chemoattractant (10\% serum). The invading or migrating cells were stained with $0.1 \%$ crystal violet and quantified by using a microscope.

\section{Quantitative real-time PCR}

Cells were transfected as already described. Total RNA was isolated from SW480 and SW620 cells using TRIzol. For miR-566 detection, $1 \mu \mathrm{g}$ of total RNA was reversetranscribed into cDNA using the miScript Reverse Transcription kit (Qiagen, Hilden, Germany). RT-PCR was performed with a miScript SYBR-Green PCR kit (Qiagen). Expression levels were normalized to U6.

\section{Western blot}

Total protein was extracted from colon cancer cells with RIPA lysis buffer (1\% Nonidet P-40, $50 \mathrm{mM}$ Tris (pH7.4), $0.5 \%$ deoxycholic acid, $100 \mathrm{mM} \mathrm{NaCl}, 10 \mathrm{mg} / \mathrm{mL}$ aprotinin, $1 \mathrm{mM}$ phenylmethylsulfonylfluoride, $0.1 \%$ sodium dodecyl sulfate, and $10 \mathrm{mg} / \mathrm{mL}$ leupeptin) [20]. Equal amounts of protein $(40 \mu \mathrm{g} / \mathrm{lane})$ were separated by $10 \%$ SDS-PAGE and transferred onto PVDF membranes. Rabbit polyclonal anti-PSKH1 antibody, mouse monoclonal anti-E-cadherin antibody, mouse monoclonal antivimentin antibody, and rabbit polyclonal anti-N-cadherin antibody (Abcam, Cambridge, MA, USA) were used to probe the proteins. The signals were measured by using an ECL detection system. $\beta$-actin (Abcam, Cambridge, MA, USA) was used as a loading reference for data analysis.

\section{Luciferase reporter assays}

Luciferase reporter assays were performed following previously described methods [21]. pGL3 control vectors (Invitrogen) containing the wild-type and mutant-type 
reporter 3'-UTR of PSKH1 (Wt-PSKH1 and Mut-PSKH1) were synthesized. SW480 cells were co-transfected with Wt-PSKH1 and miR-566 mimic or miR-NC or with MutPSKH1 and miR-566 mimic or miR-NC for $48 \mathrm{~h}$. Luciferase activity was assayed by using the Dual luciferase assay kit (Promega).

\section{RNA immunoprecipitation assay}

RNA immunoprecipitation was implemented using an EZ-Magna RIP RNA-Binding Protein Immunoprecipitation Kit (Millipore, Billerica, MA, USA) according to the manufacturer's instruction. SW480 cells transfected with anti-NC or miR-566 inhibitor were lysed into RNA immunoprecipitation lysis buffer. Cell lysate was incubated with RNA immunoprecipitation buffer containing magnetic beads conjugated with human anti-Ago2 antibody (1:50 dilution) or negative control IgG. The precipitated RNAs were subjected to real-time PCR to measure the RNA levels of miR-566 and PSKH1.

\section{Statistical analysis}

Data in this study are presented as mean \pm SD. SPSS 19.0 (IBM SPSS, Armonk, NY, USA) was used to statistical analyses. Student's $t$-test was used to detect differences between two groups. One-way ANOVA followed by LSD test was used to detect differences between three or more groups. Differences were considered significant at $p<0.05$. All data were performed in triplicate.

\section{Results \\ MiR-566 overexpression inhibits CRC cell survival and proliferation}

Prior research suggested that miR-566 is decreased in CRC [15]. In the in vitro cell assay, we measured miR566 levels in the five CRC cell lines SW480, SW620, LoVo, Caco-2 and HT29 and the control colon epithelial cell lines FHC by RT-PCR assay. The results showed that miR-566 was significantly lower in SW480, SW620, LoVo, Caco-2 and HT29 cells, when compared to the control FHC cells (Fig. 1a, $p<0.05$ ). To confirm the function of miR-566 in CRC cells, loss-of-function and gain-of-function experiments were conducted for miR-566 in SW480, SW620 and Caco-2 cells through transfecting cells with miR-566 mimic and inhibitor, respectively. As shown in Fig. 1b, the miR-566 mimic markedly increased the level of miR-566 in SW480, SW620 and Caco-2 cells, whereas the miR-566 inhibitor decreased the levels of miR-566 in of the three cell lines $(p<0.05)$. Further study indicated a

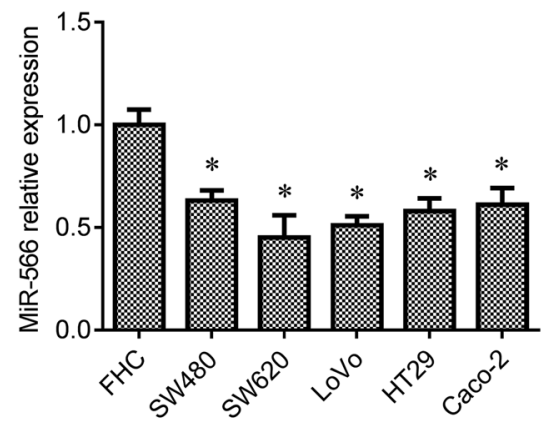

C

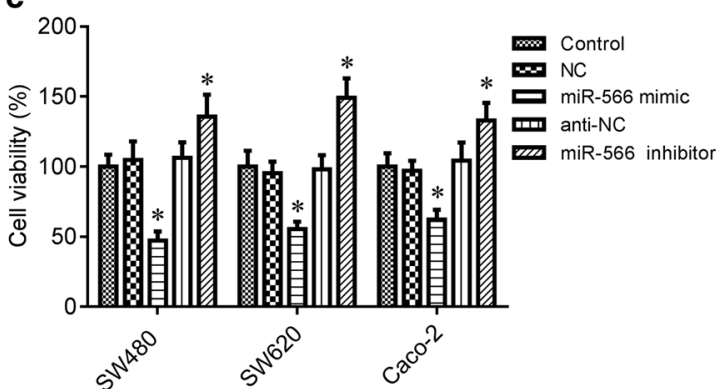

b

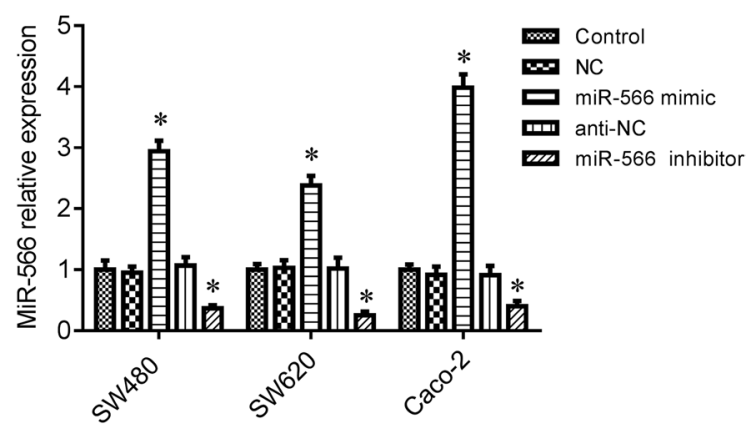

d

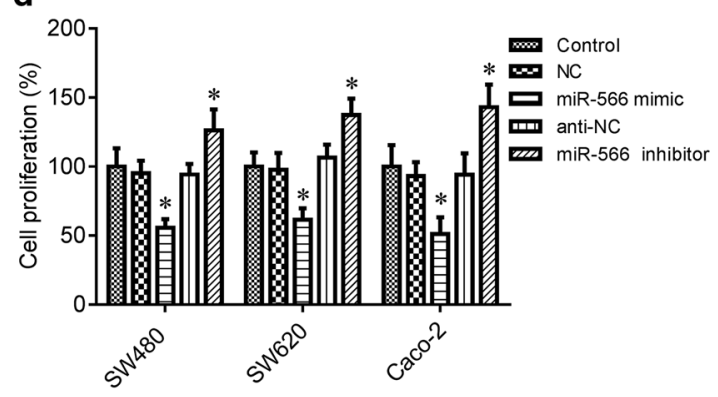

Fig. 1 miR-566 overexpression suppressed CRC cell survival and proliferation. a RT-PCR was used to measure the expression of miR-566 in CRC cell line SW480, SW620, LoVo, Caco-2 and HT29, and the control colon epithelial cell line FHC. All experiments were performed in triplicate. b RT-PCR was used to measure the expression of miR-566. c CellTiter 96 AQueous One Solution Cell Proliferation kit was used to determine cell survival. d Cell proliferation was determined by MTT assay. SW480, SW620 and Caco-2 cells were transfected with miR-566 mimic, the mimic control (NC), miR-566 inhibitor, or inhibitor control (anti-NC) for $48 \mathrm{~h}$. All experiments were performed in triplicate. ${ }^{*} p<0.05 \mathrm{vs}$. control 
that miR-566 overexpression inhibited cell survival and proliferation in SW480, SW620 and Caco-2 cells compared to the control group $(p<0.05)$, whereas inhibition of miR-566 expression by using miR-566 inhibitor promoted survival and proliferation of these cells (Fig. 1c, d, $p<0.05)$.

\section{MiR-566 overexpression inhibits CRC cell migration and invasion}

As shown in Fig. 2a, b, miR-566 mimic transfection markedly suppressed SW480 and SW620 cell migration and invasion $(p<0.05)$, while miR-566 inhibition significantly increased them $(p<0.05)$. Epithelial-mesenchymal transition (EMT) plays important roles in cell migration and invasion. We found that miR-566 overexpression markedly elevated the epithelial marker E-cadherin expression and impeded the mesenchymal markers vimentin and $\mathrm{N}$-cadherin levels, whereas its inhibition had opposite effects on E-cadherin, vimentin, and N-cadherin expression (Fig. 2c, d, $p<0.05$ ).

\section{PSKH1 is a target of miR-566}

Computational analysis suggested putative binding sites between miR-566 and 3'-UTR of human PSKH1, as shown in Fig. 3a. To confirm whether PSKH1 is a target of miR-566, we used luciferase reporter assays. Compared to the NC group, the relative luciferase activity was significantly decreased in miR-566 mimic and wild-type PSKH1 3'-UTR (Wt-PSKH1) co-transfected cells $(p<0.05)$, while no significant differences
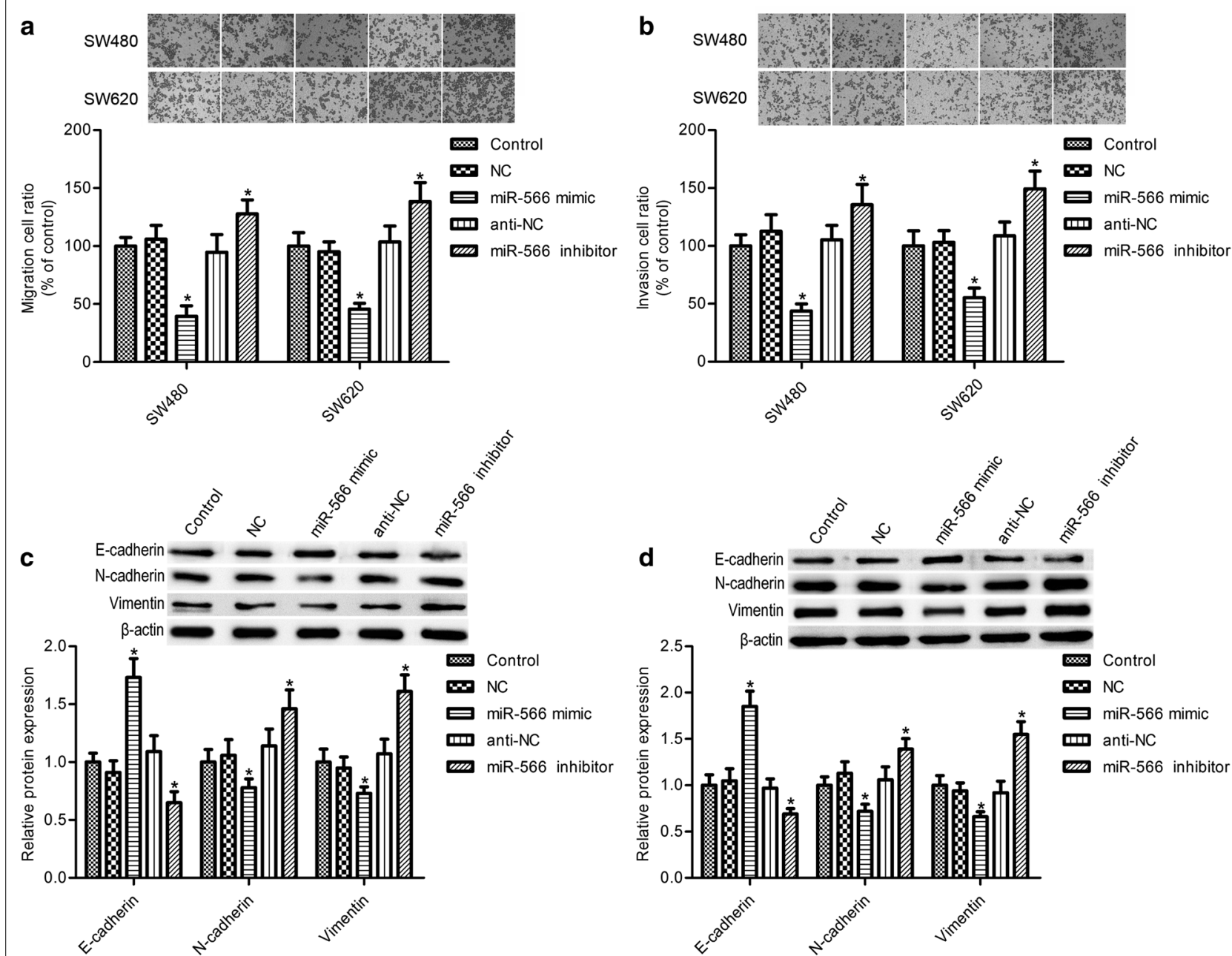

Fig. 2 miR-566 overexpression suppressed CRC cell migration and invasion. a, b SW480 and SW620 cell migration and invasion were assayed by transwell assay. Expression of epithelial-mesenchymal transition markers E-cadherin, vimentin, and N-cadherin in SW480 cells (c) and SW620 cells (d) were measured by western blot assay. SW480 and SW620 cells were transfected with miR-566 mimic, the mimic control (NC), miR-566 inhibitor, or inhibitor control (anti-NC) for $48 \mathrm{~h}$. All experiments were performed in triplicate. ${ }^{*} p<0.05$ vs. control 


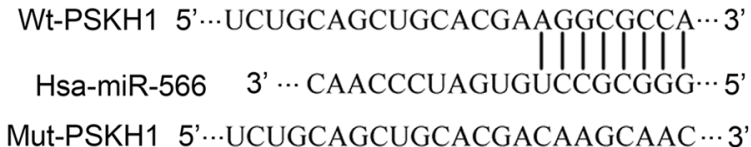

b

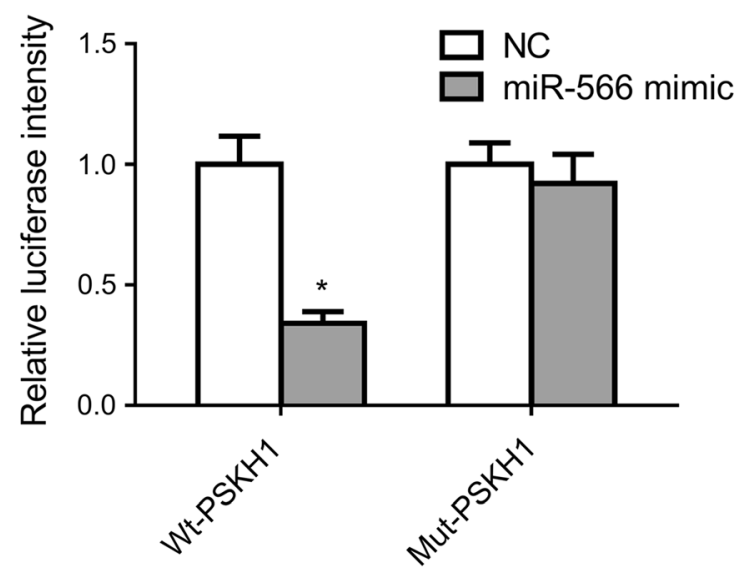

d

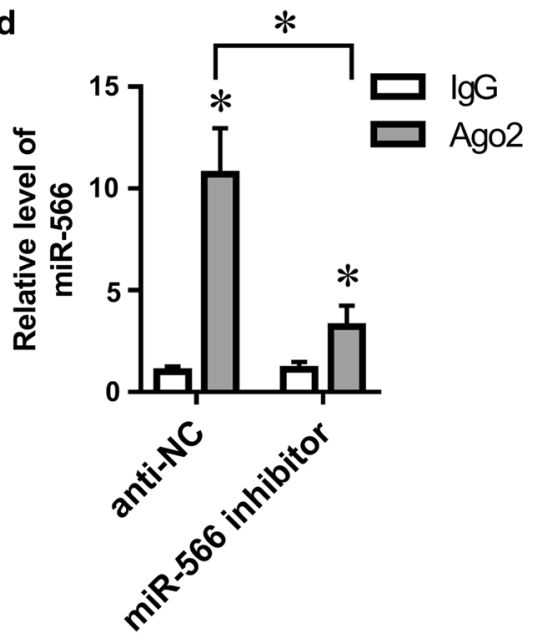

C
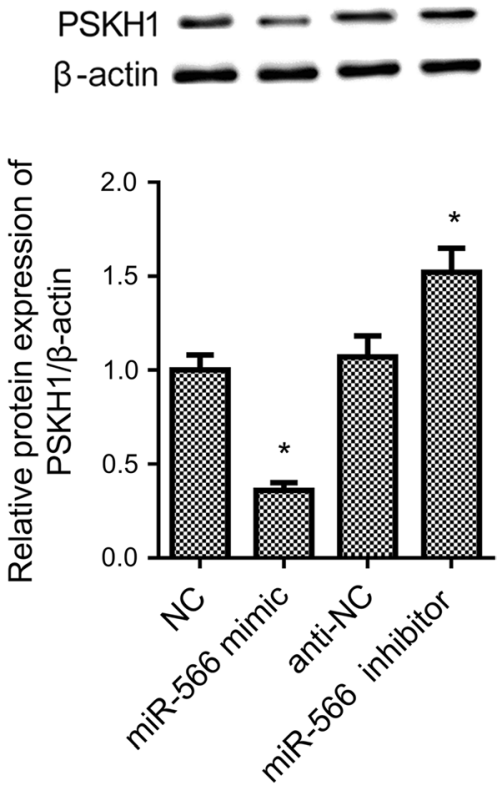

e

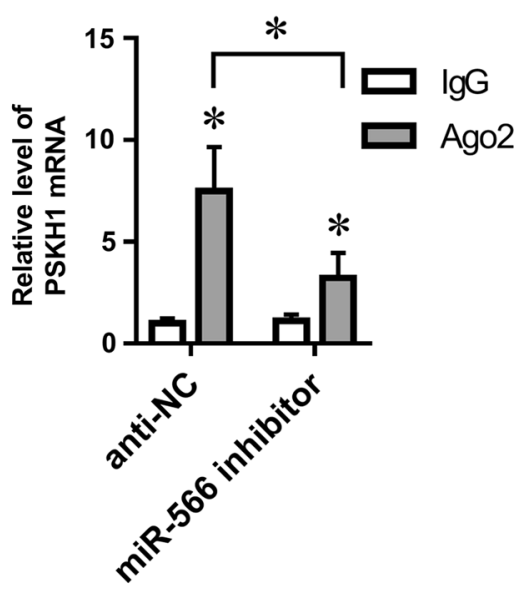

Fig. 3 miR-566 suppressed PSKH1 expression in SW480 cells. a Computational analysis suggested putative binding sites between miR-566 and 3'-UTR of human PSKH1. b SW480 cells were co-transfected with miR-566 mimic and wild-type PSKH1 3'-UTR (Wt-PSKH1) or mutant PSKH1 3'-UTR (Mut-PSKH1). Luciferase reporter assay was used to show PSKH1 is a direct target of miR-566. c PSKH1 protein expression was determined by Western blot assay. $\mathbf{d}$, e RNA immunoprecipitation assay was performed using anti-Ago 2 in SW480 cells transfected with anti-NC or miR-566 inhibitor. MiR-566 and 3'-UTR of PSKH1 mRNA levels in the anti-Ago2 or anti-lgG immunoprecipitated products were measured by RT-PCR. All experiments were performed in triplicate. ${ }^{*} p<0.05$ vs. control

were found between the miR-566 mimic and mutant PSKH1 3'-UTR (Mut-PSKH1) co-transfected group and $\mathrm{NC}$ group (Fig. 3b, $p>0.05$ ). Western blot assay further showed that PSKH1 expression was inhibited by miR-566 overexpression (Fig. 3c, $p<0.05$ ). RNA immunoprecipitation assay was performed using anti-Ago2 in SW480 cells transfected with anti-NC or
miR-566 inhibitor. The result showed that both miR566 and $3^{\prime}$-UTR of PSKH1 mRNA were detected in the anti-Ago2 immunoprecipitated products. MiR-566 inhibitor transfection significantly inhibited miR-566 and 3 '-UTR of PSKH1 mRNA levels in the anti-Ago2 immunoprecipitated products (Fig. 3d, e, $p<0.05$ ). 
Reintroduction of PSKH1 reversed the effects of miR-566 on CRC cell migration and invasion

To further validate PSKH1 as a mediator of the effects of miR-566 on CRC growth, migration, and invasion, SW480 cells were co-transfected with miR-566 mimic and pCMV-PSKH1 vector for $48 \mathrm{~h}$. The results suggested that the PSKH1 overexpression vector reversed the miR-566-mediated inhibition of SW480 cell survival (Fig. 4a). Furthermore, the PSKH1 overexpression vector increased SW480 cell proliferation, promote cell migration and invasion compared with the miR-566 overexpression group (Fig. $4 \mathrm{~b}-\mathrm{d}$ ). It was reported that both SW480 and SW620 cell lines have TP53 and KRAS mutations, but the Caco- 2 cells has only one mutation in TP53 [22]. So, Caco-2 cells were also employed in our study. The data from Caco-2 cells were in accordance with SW480 cells (Fig. 4a-d). Above results indicate that the effects of miR-566 in CRC cell growth, migration, and invasion depend on PSKH1 inhibition.

\section{Discussion}

Colorectal cancer is ranks the third diagnosed among cancer types worldwide, and it is the main cause of mortality from cancer [23]. Cancer metastasis plays roles in the advance of cancer, and in this study, we first confirmed that miR-566 is involved in colon cancer metastasis through targeting PSKH1.

MiRNAs are single-stranded, 20- to 23-nucleotidelong, noncoding RNAs that are involved in the regulation of carcinogenic pathways [24, 25]. Compared with mRNAs, miRNAs are less likely to be degraded by Ranse because of their stem-loop and small-size structure [26]; thus, this conserved molecule is easy to detect in tissue and body fluids, including saliva, urine and blood [27]. miRNAs have been well-documented to act as tumor biomarkers, and they have been shown to be associated with the development of cancer, including colorectal cancer $[28,29]$. Prior reports indicated that miRNAs are potential tumor suppressor or oncogenes by regulating
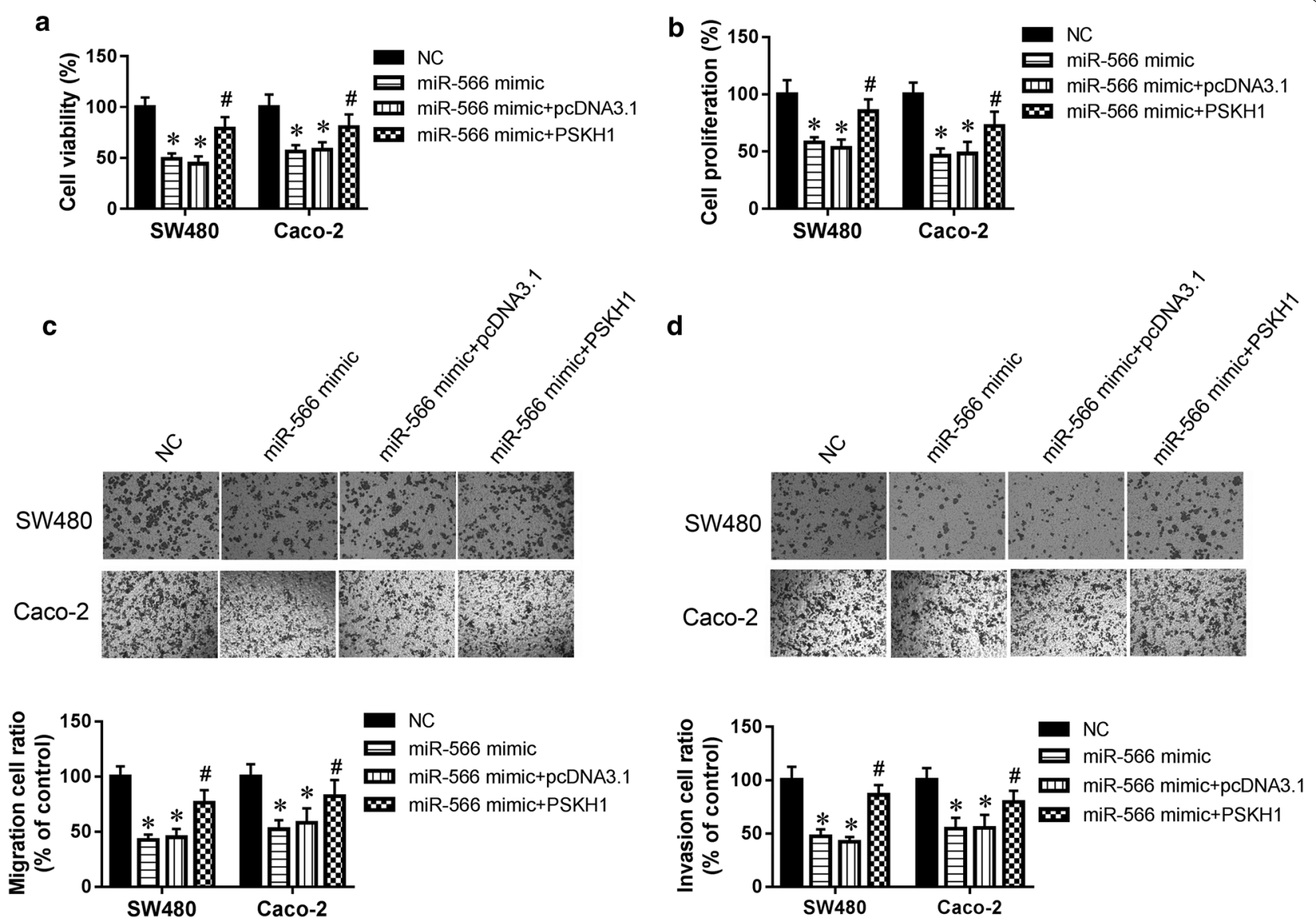

Fig. 4 PSKH1 was involved in the effect of miR-566 on CRC cell migration and invasion. a CellTiter 96 AQueous One Solution Cell Proliferation kit was used to determine survival of SW480 and Caco-2 cells. b Proliferation of SW480 and Caco-2 cells was determined by MTT assay. c Representative images and quantitative results for migration assay of SW480 and Caco-2 cells by transwell. $\mathbf{d}$ Representative images and quantitative results for invasion assay of SW480 and Caco-2 by transwell. All experiments were performed in triplicate. ${ }^{*} p<0.05$ vs. NC, ${ }^{\#} p<0.05$ vs. miR-566 mimic group 
many cell processes including the cell cycle, proliferation, apoptosis, and invasion. Pan et al. [19] reported that the oncogene miR-566 is a potential biomarker of renal cell carcinoma prognosis.

MiR-566 was aberrantly expressed in many tumor types, such as lung adenocarcinoma [30], glioblastoma [31, 32], and colon cancer [15]. Consistent with these previous reports, our study demonstrated that miR566 had a low expression level in several CRC cell lines (SW480, SW620, LoVo, Caco-2 and HT29) compared to the control colon epithelial cell line (FHC). In addition, Xiao et al. [32] previously found that miR-566 inhibition impeded glioblastoma migratory and invasive abilities through decreased VEGF expression and increased VHL expression. We also observed that miR-566 overexpression suppressed survival, proliferation, migration, and invasion in SW480 and SW620 cells.

Protein kinases play important roles in many cellular processes, such as cell cycle progression, apoptosis, cell movement, metabolism, cytoskeletal rearrangement, transcription, and cell differentiation [33, 34]. PSKH1 is an autophosphorylating human protein serine kinase with 424 amino acids that has been suggested to play structural and regulatory roles in cells and to be involved in the maintenance of the Golgi apparatus [35]. Kim et al. [16] suggested that PSKH1 is highly expressed in patients with colon cancer. To search the specific potential target gene for miR-566, an online computational algorithm TargetScan (http://www.targetscan.org) was used. PSKH1 was a potential target gene for miR-566, and potential binding sites were found in its 3'-UTR region. Our study first demonstrated that PSKH1 is a direct target of miR-566, and its expression was influenced by the level of miR-566.

\section{Conclusion}

In conclusion, the current study demonstrated that miR566 is decreased in colon cancer cells, and overexpression of miR-566 inhibited cancer cell growth and metastasis. In addition, we found that PSKH1 is a target of miR-566, and reintroduction of PSKH1 expression reversed the effects of miR-566 on cancer cell growth and metastasis.

\section{Authors' contributions}

YZ and RX conceived of the study. SZ contributed the materials used in this study. YZ, SZ and JY performed research and analyzed data. YZ and RX wrote the paper. All authors read and approved the final manuscript.

\section{Funding}

None.

Availability of data and materials

All data generated or analyzed during this study are included in this published article.
Ethics approval and consent to participate Not applicable.

\section{Consent for publication}

Not applicable.

\section{Competing interests}

The authors declare that they have no competing interests.

\section{Author details}

${ }^{1}$ Endoscopy Center, China-Japan Union Hospital of Jilin University, No. 126 Sendai Street, Changchun 130033, Jilin, China. ${ }^{2}$ Department of Nephrology, China-Japan Union Hospital of Jilin University, Changchun 130033, Jilin, China. ${ }^{3}$ Department of Vascular Surgery, China-Japan Union Hospital of Jilin University, Changchun 130033, Jilin, China.

Received: 6 September 2019 Accepted: 30 November 2019

Published online: 11 December 2019

References

1. Fitzmaurice C, Dicker D, Pain A, Hamavid H, Moradi-Lakeh M, Maclntyre M, Allen C, Hansen G, Woodbrook R, Wolfe C, et al. The global burden of cancer 2013. JAMA Oncol. 2015;1 (4):505-27.

2. Fitzmaurice C, Allen C, Barber R, Barregard L, Bhutta Z, Brenner H, Dicker $D$, Chimed-Orchir O, Dandona R, Dandona L, et al. Global, regional, and national cancer incidence, mortality, years of life lost, years lived with disability, and disability-adjusted life-years for 32 cancer groups, 1990 to 2015: a systematic analysis for the global burden of disease study. JAMA Oncol. 2017;3(4):524-48.

3. Li Z, Li N, WU M, Li X, Luo Z, Wang X. Expression of miR-126 suppresses migration and invasion of colon cancer cells by targeting CXCR4. Mol Cell Biochem. 2013;381(1-2):233-42.

4. Kudo-Saito C, Shirako H, Takeuchi T, Kawakami Y. Cancer metastasis is accelerated through immunosuppression during Snail-induced EMT of cancer cells. Cancer Cell. 2009;15(3):195-206.

5. Soreide K, Berg M, Skudal B, Nedreboe B. Advances in the understanding and treatment of colorectal cancer. Discov Med. 2011;12(66):393-404.

6. Wang J, Wang X, Liu F, Fu Y. microRNA-335 inhibits colorectal cancer HCT116 cells growth and epithelial-mesenchymal transition (EMT) process by targeting Twist1. Pharmazie. 2017;72(8):475-81.

7. Yao G, Zhang Y, Chen P, Ren X. MicroRNA-544 promotes colorectal cancer progression by targeting forkhead box O1. Oncol Lett. 2018;15(1):991-7.

8. Cellura D, Pickard K, Quaratino S, Parker H, Strefford J, Thomas G, Mitter R, Mirnezami A, Peake N. miR-19-mediated inhibition of transglutaminase-2 leads to enhanced invasion and metastasis in colorectal cancer. Mol Cancer Res. 2015;13(7):1095-105.

9. Hu W, Coller J. What comes first: translational repression or mRNA degradation? The deepening mystery of microRNA function. Cell Res. 2012;22(9):1322-4.

10. Wu N, Fesler A, Liu H, Ju J. Development of novel miR-129 mimics with enhanced efficacy to eliminate chemoresistant colon cancer stem cells. Oncotarget. 2018;9(10):8887-97.

11. Li J, Mao X, Wang X, Miao G. miR-433 reduces cell viability and promotes cell apoptosis by regulating MACC1 in colorectal cancer. Oncol Lett. 2017;13(1):81-8.

12. Qin $Y$, Huo $Z$, Song $X$, Chen $X$, Tian $X$, Wang $X$. mir-106a regulates cell proliferation and apoptosis of colon cancer cells through targeting the PTEN/PI3K/AKT signaling pathway. Oncol Lett. 2018;15(3):3197-201.

13. Chen Z, Han S, Huang W, Wu J, Liu Y, Cai S, He Y, Wu S, Song W. MicroRNA-215 suppresses cell proliferation, migration and invasion of colon cancer by repressing Yin-Yang 1. Biochem Biophys Res Commun. 2016;479(3):482-8.

14. Sun J, Zhou J, Dong M, Sheng W. Dysregulation of MicroRNA-543 expression in colorectal cancer promotes tumor migration and invasion. Mol Carcinog. 2017;56(1):250-7.

15. Drusco A, Nuovo G, Zanesi N, Di Leva G, Pichiorri F, Volinia S, Fernandez C, Antenucci A, Costinean S, Bottoni A, et al. MicroRNA profiles discriminate among colon cancer metastasis. PLoS ONE. 2014;9(6):e96670. 
16. Kim S, Ahn T, Lee E, Do I, Lee S, Park S, Park J, Park Y, Lim H, Kang W, et al. Exploratory biomarker analysis for treatment response in KRAS wild type metastatic colorectal cancer patients who received cetuximab plus irinotecan. BMC Cancer. 2015;15:747.

17. Brede G, Solheim J, Tröen G, Prydz H. Characterization of PSKH1, a nove human protein serine kinase with centrosomal, golgi, and nuclear localization. Genomics. 2000;70(1):82-92.

18. Brede G, Solheim J, Prydz H. PSKH1, a novel splice factor compartmentassociated serine kinase. Nucleic Acids Res. 2002;30(23):5301-9.

19. Pan X, Quan J, Li Z, Zhao L, Zhou L, Jinling X, Weijie X, Guan X, Li H, Yang $S$, et al. miR-566 functions as an oncogene and a potential biomarker for prognosis in renal cell carcinoma. Biomed Pharmacother. 2018;102:718-27

20. Zhou W, Li X, Liu F, Xiao Z, He M, Shen S, Liu S. MiR-135a promotes growth and invasion of colorectal cancer via metastasis suppressor 1 in vitro. Acta Biochim Biophys Sin. 2012;44(10):838-46

21. Wang B, Sun F, Dong N, Sun Z, Diao Y, Zheng C, Sun J, Yang Y, Jiang D. MicroRNA-7 directly targets insulin-like growth factor 1 receptor to inhibit cellular growth and glucose metabolism in gliomas. Diagn Pathol. 2014;9:211.

22. Berg KCG, Eide PW, Eilertsen IA, Johannessen B, Bruun J, Danielsen SA, Bjornslett M, Meza-Zepeda LA, Eknaes M, Lind GE, et al. Multi-omics of 34 colorectal cancer cell lines-a resource for biomedical studies. Mol Cancer. 2017;16(1):116.

23. Marikar F, Jin G, Sheng W, Ma D, Hua Z. Metallothionein $2 A$ an interactive protein linking phosphorylated FADD to NF-KB pathway leads to colorectal cancer formation. Chin Clin Oncol. 2016;5(6):76.

24. Catto J, Alcaraz A, Bjartell A, De Vere White R, Evans C, Fussel S, Hamdy F, Kallioniemi O, Mengual L, Schlomm T, et al. MicroRNA in prostate, bladder, and kidney cancer: a systematic review. Eur Urol. 2011;59(5):671-81.

25. Yang J, Ma D, Fesler A, Zhai H, Leamniramit A, Li W, Wu S, Ju J. Expression analysis of microRNA as prognostic biomarkers in colorectal cancer. Oncotarget. 2017:8(32):52403-12.

26. Manne U, Jadhav T, Putcha B, Samuel T, Soni S, Shanmugam C, Suswam E. Molecular biomarkers of colorectal cancer and cancer disparities: current status and perspective. Curr Colorectal Cancer Rep. 2016;12(6):332-44.
27. Tutar L, Tutar E, Tutar Y. MicroRNAs and cancer; an overview. Curr Pharm Biotechnol. 2014;15(5):430-7.

28. Tan W, Liu B, Qu S, Liang G, Luo W, Gong C. MicroRNAs and cancer: key paradigms in molecular therapy. Oncol Lett. 2018;15(3):2735-42.

29. Bhome R, Goh R, Bullock M, Pillar N, Thirdborough S, Mellone M, Mirnezami R, Galea D, Veselkov K, Gu Q, et al. Exosomal microRNAs derived from colorectal cancer-associated fibroblasts: role in driving cancer progression. Aging. 2017;9(12):2666-94.

30. Rani S, Gately K, Crown J, O'Byrne K, O'Driscoll L. Global analysis of serum microRNAs as potential biomarkers for lung adenocarcinoma. Cancer Biol Ther. 2013;14(12):1104-12.

31. Zhang K, Zhou X, Han L, Chen L, Chen L, Shi Z, Yang M, Ren Y, Yang J, Frank T, et al. MicroRNA-566 activates EGFR signaling and its inhibition sensitizes glioblastoma cells to nimotuzumab. Mol Cancer. 2014;13:63.

32. Xiao B, Zhou X, Ye M, Lv S, Wu M, Liao C, Han L, Kang C, Zhu X. MicroRNA-566 modulates vascular endothelial growth factor by targeting Von Hippel-Landau in human glioblastoma in vitro and in vivo. Mol Med Rep. 2016;13(1):379-85.

33. Manning G, Whyte D, Martinez R, Hunter T, Sudarsanam S. The protein kinase complement of the human genome. Science. 2002;298(5600):1912-34.

34. Blume-Jensen P, Hunter T. Oncogenic kinase signalling. Nature. 2001;411(6835):355-65

35. Brede G, Solheim J, Stang E, Prydz H. Mutants of the protein serine kinase PSKH1 disassemble the Golgi apparatus. Exp Cell Res. 2003;291(2):299-312

\section{Publisher's Note}

Springer Nature remains neutral with regard to jurisdictional claims in published maps and institutional affiliations.
Ready to submit your research? Choose BMC and benefit from:

- fast, convenient online submission

- thorough peer review by experienced researchers in your field

- rapid publication on acceptance

- support for research data, including large and complex data types

- gold Open Access which fosters wider collaboration and increased citations

- maximum visibility for your research: over $100 \mathrm{M}$ website views per year

At $\mathrm{BMC}$, research is always in progress.

Learn more biomedcentral.com/submissions 